\title{
Study on English teaching practice in primary school and lower grades based on English picture book reading
}

\section{Lingling Qin}

Foreign Languages Department of Yuzhang Normal College

Keywords: primary school, the lower grades, English picture book reading, Teaching, research

\begin{abstract}
Learning any language requires a lot of reading. English reading ability is a very important part of English language skills, in addition, learning English in the lower grades of primary schools requires original English texts particularly. As for the teachers, how to create opportunities for students to have access to authentic English texts and experience more authentic English culture has become an urgent problem that need to be solved. Some researchers proposed that the reading of English picture books should provide primary school students with more opportunities and time to contact and read English to stimulate students' interest in it, and improve their English reading ability and comprehension, and the author feels the same way at this point. However, this paper studies the application and practice of English picture books in English teaching in junior grade of primary school, and mainly discuss the following research questions: first, the existing problems in primary school English picture book teaching; second, the advantages of English picture book teaching in the lower grade of primary school; third, the practical strategy of using English picture book teaching model reasonably in primary school; fourth, problems that need to be paid attention to in the teaching of English picture books in the lower grade of primary school.
\end{abstract}

As economic globalization and China's economic trade and exchanges with the world become more and more frequent and closer, foreign languages that are widely used in the world have become a language that China's society needs to increase. English courses are offered in primary school, middle school and university. Education of primary school gradually permeates into English teaching, hoping to cultivate children's English language sense from primary school.

The concept of picture books originated from Japan, which was the Japanese general term for the picture originally. Actually, it refers to a book that interprets a story together with "picture" and "text". Primary school English picture book teaching is to show the words and syntax learning in the form of pictures to enrich students' emotions. The new curriculum standards for primary school English in the lower grades emphasize that students should be able to understand the small stories with the help of pictures. It is under the guidance of the new curriculum standard that the primary school English picture book teaching becomes the current important teaching mode. Thus, this paper conducts this study in order to promote the teaching of English picture books in the lower grades of primary schools better.

\section{Current problems in primary school English picture book teaching}

\subsection{Teachers have insufficient understanding of the characteristics of English picture books}

Through the in-deep interviews, the author found that many teachers' understanding of the features of English picture books and picture books teaching is still in the primary stage, they believe that picture books can only supplement the existing classroom teaching of primary school English. Therefore, in the primary school English picture book teaching schools, teachers have different understanding of picture book teaching, resulting in the emergence of two completely different classroom teaching methods.

One is to carry out picture book teaching centering on the teaching form of the original textbooks. In this teaching mode, teachers often adopt the traditional teaching method of textbooks with 
vocabulary and functional sentence patterns as the teaching emphasis. The characteristics of picture-book teaching are ignored by learning English knowledge through picture-book stories. In another form of picture book teaching, teachers add picture books as primary school students' extracurricular learning materials to students' in-class reading, so as to improve students' English reading, thus promoting students' learning of English knowledge. Although the latter kind of picture book teaching cultivated students' independent reading ability, it weakened the guiding role of teachers.

\subsection{Teachers lack the teaching ideas and methods of picture book teaching}

Compulsory education English course standard (2011 edition) has made relevant regulations on the learning ability of primary school students' English stories, requiring them to understand, read and tell simple stories with the help of pictures, perform small stories or short plays , and sing simple English songs and ballads with the help of teachers. In order to achieve these learning abilities, teachers must have the teaching ideas and methods related to picture book teaching.

However, due to the short time of using picture books, many English teachers in primary schools in China do not have a good understanding of the purpose of picture books and the corresponding teaching methods. What's more, in the process of reading picture books for primary school students, if teachers lack relevant teaching concepts, they cannot improve the teaching system and the efficiency. Therefore, we should explore ways of teaching in accordance with the learning habits of primary school students to improve this situation.

\subsection{Teachers are relatively backward in the research of picture books}

Due to the late application of English picture book reading in domestic English education, the exploration and practice on this aspect are relatively backward. In addition, the mutual reference between textbooks and picture books has gradually become an important issue for people to pay attention to under the condition of fixed English textbooks and limited English lessons in primary school.

\section{The advantage of English picture book teaching in elementary school}

Primary school English picture book teaching refers to show students English words and sentence by combining the picture and the words to let them understand English by understanding the pictures, it is a new teaching model which is based on ability and abandons the traditional pure English teaching mode of memory, and this is a big improvement on the teaching of English. Generally speaking, picture book teaching in primary school has the following three advantages:

\subsection{To deepen students' understanding of English}

All the pictures in the picture book are drawn according to English words and semantics, which can fully express the meaning of English. Students will understand English more thoroughly When they understand the pictures.

\subsection{Increase students' interest in learning}

Primary school students are very interested in pictures. When students learn English knowledge, reading picture books is just like reading comics and comic books. In this way, students will be more interested in English as well as in learning English.

\subsection{Enrich students’ emotions}

In the previous monotonous teaching of words and vocabulary, it always feels boring although students have memorized English knowledge. And after teaching with picture books, students' emotions will be mobilized through the stories and situations in picture books, so as to enrich their emotions and meet the needs of emotional teaching required by the new curriculum standards. 


\section{The strategy of using English picture books reasonably in the lower grades of primary school}

In order to achieve reasonable use of English in primary school picture books, we should combine the advantages of textbooks with English teaching to give play to its unique advantages after understanding its advantages. In the specific teaching strategy, we should grasp the following three aspects.

\subsection{Use English picture books to teach vocabulary}

It is undeniable that the basis of English teaching in primary schools is still word memorization, but the efficiency of word memorization and the firmness and interest of word memorization are closely related to the teaching methods. In the teaching of vocabulary, picture books can be fully used for word memorization and recognition. Because in the picture book of primary school English, the object or meaning represented by the word can be intuitively represented by the picture. The combination of picture and text can make the pupils have a more comprehensive and profound understanding of the word, which also conforms to the internalization process of education from image to abstract. For example, in the lesson of "My Family", the words involved are "sister" and "little", which can lead the primary school students to perceive the picture content and let them know the relationship between the characters in the picture, so as to understand the words like "sister" and "little". To sum up, when teaching vocabulary, students should not be taught words without picture books. On the contrast, students should combine words with picture books to improve their understanding and memory of words.

\subsection{Combine the English picture book situation to carry on the semantic teaching}

In primary school English teaching, besides the basic task of memorizing words, another basic requirement is to understand and master phrases or sentences, especially basic sentence patterns and grammar. If we simply teach English dialogue, we are equivalent to learning Chinese, only changing Chinese into English. Therefore, in the teaching of syntactic and sentence patterns, why not combine these syntactic and patterns with corresponding scenes? And students can be integrated into the scenes with the help of scenes. In this way, some sentences can be understood through various ways, such as understanding, association and life-like inspiration, and all of these way can help the primary school students to understand the meaning. Through the semantic teaching of self-understanding, students' knowledge self-construction conforms to the basic principles of constructivism and improves the efficiency of primary school. For example, in the course of learning "Myself”, two mice were set in the English picture book of primary school, and the scene they drew was the first time they met. Such animal pattern scene enables students to guess the specific situation and the content to be expressed in general, which is conducive to learning "How old are you?” and "I am five years old” and other basic phrases and sentences.

\subsection{Design picture books to fit the teaching objectives}

The teaching process is a design made by each teacher according to the teaching goal and his own teaching idea and knowledge reserve. Therefore in the teaching design, not every picture books in the teaching material can meet the needs of teaching, especially in the synonyms and antonyms or different sentence patterns of comparison analysis teaching, it is difficult to find the proper pictures from the picture books, this requires English teacher not only constrained by textbooks, but also take some proper picture books teaching according to their own teaching goal, such as let the students to experience and to enhance English learning efficiency through the brief strokes, or a rough drawing situation that you want to express your meaning. Take another one for example, when learning the differences of big, little, small and other words, students can draw out the size patterns of the same object with the help of the stick figure, and match the words or phrases to enhance the differences and help students understand. 


\section{Problems that need to be paid attention to in the teaching of English picture books in the lower grade of primary school}

\subsection{Pay attention to the selection of English picture books}

One is to choose English picture books according to students' cognitive development at different stages. The concrete image thinking of junior grade and the formation and development stage of abstract thinking of middle and senior grade are important basis of picture book selection. In particular, graded reading based on different grading evaluation is valued by the English teaching circle for its evaluation standard and scientific nature. The second is to choose the corresponding picture books according to different topics in English textbooks. The content of picture books can be selected and corresponded according to the topic of the textbook to supplement and expand the teaching of vocabulary and dialogue in the textbook. Third, the choice of picture books should be diversified. The picture books read by primary school students should be diversified. Different ways of thinking of different authors will enable students to have more open thinking and broad perspectives, which will be more conducive to their future development of English learning.

\subsection{Promote students' positive experience in English reading}

Reading English picture books is one of the important ways to cultivate and improve students' interest in learning English. Therefore, when primary school students start to read picture books, the teaching should start from the cultivation of students' interest in reading to develop their good reading habits and enthusiasm for English learning and language sense. At the same time, we can use various forms of picture books to communicate and display, increase the interaction and share between students, and promote the improvement of English learning.

\subsection{Establish a diversified reading evaluation method for English picture books}

The evaluation of picture book teaching is not suitable for the traditional evaluation model of English teaching, but mainly encourages the establishment of students' interest in reading and the improvement of their reading comprehension ability. Therefore, the assessment of vocabulary, sentence patterns, grammar and other aspects is not within the main evaluation scope of picture book reading. At present, the evaluation of picture book reading mainly evaluates students' reading process, reading behavior and attitude through reading comprehension test and questionnaire, which also lays a foundation for the composition of the evaluation system of picture book teaching in the future.

\section{Conclusion}

To sum up, the primary school English picture book is a teaching material designed based on the characteristics of primary school students and the teaching needs. Its biggest advantage is to make English learning vivid and interesting. Teachers should grasp the characteristics of picture book teaching and use the teaching materials reasonably. The specific application should be combined with English picture books to carry on the word teaching skillfully; combining the situation to carry on the semantic teaching; design picture books to fit the teaching objectives and so on, so that let primary school English picture book teaching to give play to the advantages of improving primary school students' English learning.

\section{Acknowledgement}

This paper is derived from the 2017 Jiangxi provincial higher education reform research project "a practical study of English teaching in elementary school and lower grade based on English picture book reading", project number: JXJG-17-43-6. 


\section{References}

[1] Fenghui Wu. A preliminary study on the application of English picture books in the English teaching of elementary and junior grades [J]. Science public (science education), 2015, (12).

[2] Yi Zhao. A practical study on English picture book reading teaching in elementary school in junior grade [D]. Shanghai normal university, 2015.

[3] Min Zhang. Application exploration of picture book teaching in English classroom teaching in lower grades [J]. Primary school teaching research, 2015, (34).

[4] Wenhua Zhang, yuan Sun. Design of primary school English picture book reading activity [J]. Basic English education, 2015, (4). 